\title{
Association of cardiometabolic risk factors and dental caries in a population-based sample of youths
}

\author{
Roya Kelishadi ${ }^{*}$, Shiva Mortazavi ${ }^{2}$, Tavakol R Hossein ${ }^{3}$, Parinaz Poursafa ${ }^{4}$
}

\begin{abstract}
Background: Cardiovascular disease (CVD) risk factors begin from early life and track onto adulthood. Oral and dental diseases share some risk factors with CVD, therefore by finding a clear relation between dental diseases and cardiometabolic risk factors; we can then predict the potential risk of one based on the presence of the other. This study aimed to compare the prevalence of dental caries between two groups of age-matched adolescents with and without CVD risk factors.

Methods: In this case-control study, the decayed, missing and filled surfaces (DMFS), based on the criteria of the World Health Organization, were compared in two groups of equal number ( $n=61$ in each group) of populationbased sample of adolescents with and without CVD risk factors who were matched for sex and age group.

Results: The study participants had a median age 13 y 5 mo, age range 11 y 7 mo to 16 y 1 mo, with male-tofemale proportion of 49/51. We found significant difference between the mean values of DMFS, body mass index, waist and hip circumferences, as well as serum lipid profile in the case and control groups. Significant correlations were documented for DMFS with TC $(r=0.54, p=0.02)$, LDL-C $(r=0.55, p=0.01)$ and TG $(r=0.52, p=0.04)$ in the case group; with LDL-C $(r=0.47, p=0.03)$ in the whole study participants and with TC in control $s(r=0.45$, $p=0.04)$.
\end{abstract}

Conclusions: Given the significant associations between dental caries and CVD risk factors among adolescents, more attention should be paid to oral health, as one of the topics to be taken into account in primordial/primary prevention of cardiometabolic disorders.

\section{Introduction}

Cardiovascular diseases (CVD) are the leading cause of mortality worldwide [1]. According to World Health Organization (WHO) estimates, by 2020, non-communicable diseases notably CVD will account for approximately three quarters of all deaths in the developing world [2]. There is a large body of evidence that CVD begin early in life, persist from childhood to adolescence and results in symptomatic diseases in adult life. Interest in childhood precursors to chronic diseases is increasing because the behavioural and biological risk factors for chronic diseases persist from childhood into adulthood $[3,4]$.

\footnotetext{
* Correspondence: kelishadi@med.mui.ac.ir

${ }^{1}$ Paediatric Preventive Cardiology Department, Isfahan Cardiovascular Research Centre (WHO Collaborating Centre in Eastern Mediterranean Region), Isfahan University of Medical Sciences, Isfahan, Iran
}

New research is reinforcing the longstanding belief that an association exists between improper oral health and CVD [5-11].

There are known risk factors that make the cardiovascular system susceptible to diseases. Many of these risk factors are now brought to the life of young adolescents. Therefore, a high-risk life style from the early ages, leads to a higher risk of the heart diseases later in life. Diet, physical activity, and obesity have been highlighted among these risk factors [3,4]. There are also risk factors that lead to dental caries and poor oral health [12-14]. Dental caries is the most common chronic childhood disease. Even young children can be affected because a child's tooth is susceptible to decay as soon as it begins to erupt. Dental caries remains a significant problem in some populations, particularly certain racial 
and ethnic groups and in children from low social economic status regions of the world $[14,15]$.

Various biological and socio-demographic factors, notably dietary factors, increase the risk of dental caries $[16,17]$. In turn, dental caries is suggested as one of oral health disorders related with health and well being in childhood [18] and CVD later in life as documented by a birth cohort study showing the associations of dental caries with angina pectoris [19].

Therefore finding association between dental caries and oral hygiene status with CVD risk factors in children and adolescents might be useful in preventive control measures against CVD from early life. The main objective of this investigation was to compare dental caries prevalence between two groups of matched adolescents with and without cardiometabolic risk factors.

\section{Methods}

This study was conducted in the Paediatric Preventive Cardiology Department, Isfahan Cardiovascular Research Centre (ICRC), a WHO-Collaborating Centre in the Eastern Mediterranean region, and affiliated to Isfahan University of Medical Sciences, Isfahan, Iran. It was designed as a prospective case-control study to determine and compare decayed, missing, filled, surfaces (DMFS) in two groups of equal number $(n=61$ in each group) of adolescents with and without CVD risk factors, considered as case and control groups, respectively. The two groups were matched for age group and sex distribution.

They were selected among participants of a community-based cross-sectional study of CVD risk factors in adolescents living in Isfahan, the second largest city in Iran. Those subjects with chronic disease and or longterm medication use or on specially recommended diets were excluded. The ICRC Ethics Committee (NIH Code: FWA 0000t8578) approved the study. Written informed consent was obtained from parents and oral assent from eligible adolescents.

The same team of paediatricians, general physicians and nurses examined all study participants. Based on the recommendations of Lohman et al. [20], three height $(\mathrm{Ht})$ and weight (Wt) measurements were collected by calibrated instruments, and their average were used to compute the body mass index (BMI). BMI was converted to percentile by using the CDC (Centers for Disease Control and Prevention. Atlanta, GA 30333, USA) reference data [21]. Blood pressure (BP) was measured using mercury sphygmomanometers under standard protocol. The readings at the first and the fifth Korotkoff phase were taken as systolic and diastolic BP (SBP and DBP), respectively. The average of the two $\mathrm{BP}$ measurements was recorded and included in the analysis [22].
Participants were instructed to fast for $12 \mathrm{~h}$ before the screening. Compliance with fasting was determined by interview on the morning of examination while one of the parents accompanied his/her child. Blood samples were taken from the antecubital vein between 8:00 and 9:30 am. The blood samples were centrifuged for 10 $\mathrm{min}$ at $3000 \mathrm{rpm}$ within $30 \mathrm{~min}$ of venipuncture. Fasting blood glucose (FBG), total cholesterol (TC), high density lipoprotein cholesterol (HDL-C), low density lipoprotein cholesterol (LDL-C), and triglycerides (TG) were measured by enzymatic method using autoanalyzer (Hitachi Model 902, Hitachi Ltd., Japan). HDL-C was determined after dextran sulphate-magnesium chloride precipitation of non-HDL-C [23]. Serum lipid profile and glucose were examined in ICRC central laboratory, which meets the standards of the National Reference laboratory (WHO Collaborating Centre in Tehran) and is also under an international quality control initiative.

CVD risk factors were defined according to the guidelines of the American Heart Association for identification of children and adolescents at high risk of CVD i.e. BMI $\geq 85$ th percentile for age and sex, TC $>200 \mathrm{mg} / \mathrm{dL}$, $\mathrm{LDL}-\mathrm{C}>130 \mathrm{mg} / \mathrm{dL}, \mathrm{TG}>150 \mathrm{mg} / \mathrm{dL}$ as well as systolic and diastolic blood pressure $>90^{\text {th }}$ percentile for age, sex and height were considered to be elevated and HDL$\mathrm{C}<35 \mathrm{mg} / \mathrm{dL}$ was considered to be low [24]. According to the recommendation of the American Diabetes Association, $\mathrm{FBG} \geq 100 \mathrm{mg} / \mathrm{dL}$ was considered to be elevated [25]. Those adolescents with each of these risk factors were considered as the case group.

An expert dentist examined the decayed, missing, filled, surfaces (DMFS) of participants in both case and control groups blindly. Clinical examinations were carried out under indirect sunlight, using a sickle explorer, flat-surface mouth mirror after drying teeth with sterile gauze. Dental caries status was evaluated using the WHO caries diagnostic criteria for DMFS of teeth [26].

Data were transferred to SPSS statistical PC software version 11 (SPSS, Inc., Chicago, IL, USA) via a third person blind operator. The variables assessed were compared in the case and control groups by independent $t$ and Mann-Whitney U tests. The correlation of DMFS with other variables was determined in the whole study participants and in the case and control groups separately by Spearman correlation test.

\section{Results}

The study population comprised a total of 122 participants with median age 13 y 5 mo, age range 11 y 7 mo to 16 y 1 mo, and male-to-female proportion of 49/51. Table 1 presents the characteristics of participants of both groups. It shows significant differences between the mean values of DMFS, BMI, WC, HiC, TC, LDL-C, HDL-C, and TG between the case and control groups; 
Table 1 Comparison of variables ${ }^{\mathrm{a}}$ studied in the case and control groups

\begin{tabular}{lll}
\hline VARIABLES & CONTROL & CASE \\
\hline Age (years) & $13.5 \pm 1.40$ & $13.5 \pm 1.40$ \\
Body mass index $\left(\mathrm{kg} / \mathrm{m}^{2}\right)^{*}$ & $20.7 \pm 3.25$ & $25.4 \pm 9.72$ \\
Waist circumference $(\mathrm{cm})^{*}$ & $77.8 \pm 7.89$ & $86.4 \pm 13.13$ \\
Hip circumference $(\mathrm{cm})^{*}$ & $91.6 \pm 8.46$ & $99.8 \pm 12.16$ \\
Decayed, missing, filled, surface (DMFS) & $0.4 \pm 0.03$ & $0.8 \pm 0.04$ \\
Diastolic blood pressure $(\mathrm{mmHg})$ & $64.3 \pm 8.98$ & $65.8 \pm 9.33$ \\
Systolic blood pressure $(\mathrm{mmHg})$ & $103.3 \pm 10.80$ & $106.9 \pm 10.62$ \\
Fasting blood glucose $(\mathrm{mg} / \mathrm{dL})$ & $83.1 \pm 5.36$ & $84.9 \pm 14.61$ \\
Total cholesterol $(\mathrm{mg} / \mathrm{dL})^{*}$ & $163.0 \pm 21.16$ & $194.1 \pm 32.12$ \\
LDL- cholestrol $(\mathrm{mg} / \mathrm{dL})^{*}$ & $97.1 \pm 19.33$ & $121.4 \pm 32.82$ \\
HDL- cholesterol $(\mathrm{mg} / \mathrm{dL})^{*}$ & $47.9 \pm 9.40$ & $43.6 \pm 12.24$ \\
Triglycerides (mg/dL)* & $99.6 \pm 31.57$ & $137.3 \pm 65.11$ \\
\hline
\end{tabular}

${ }^{a}$ : mean $\pm \mathrm{SD}^{*}, \mathrm{p}<0.05$ between case and control groups

whereas the mean FBG, DBP and SBP was not significantly different.

The Spearman correlation analysis showed significant relationships of DMFS with LDL-C $(r=0.47, \mathrm{p}=0.03)$ in the whole study participants and with $\mathrm{TC}$ in the control group $(r=0.45, p=0.04)$. In the case group, significant correlations were documented for TC $(\mathrm{r}=0.54$, $\mathrm{p}=0.02)$, LDL-C $(\mathrm{r}=0.55, \mathrm{p}=0.01)$ and $\mathrm{TG}(\mathrm{r}=0.52$, $\mathrm{p}=0.04)$.

\section{Discussion}

This study showed higher prevalence of dental caries among adolescents with higher risk of CVD and revealed significant associations between dental caries and CVD risk factors.

These results in the paediatric age group confirmed those of previous studies conducted with elder subjects that showed significant association of dental disease with CVD and its risk factors [27] Same results have been reported in a community-based study conducted among Swedish youths that showed higher number of caries free 15-year-old urban adolescents among those with low atherosclerosis risk [28].

A prevention program in Sweden studied dietary intake, CVD risk factors and dental caries in five crosssectional groups of 15 -year-old adolescents during 5 years. It revealed that dental caries were associated with increased BMI and CVD risk factors [29]. The association of dental caries with cardiovascular events remains controversial. While a study did not document any association between dental caries and acute ischemic stroke or transient ischemic attack [30], a birth cohort confirmed the associations of dental caries with angina pectoris [19].

Streptococcus mutans, the primary etiological agent of dental caries is also found as the most prevalent bacterial species in clinical samples of patients who underwent heart valve and atheromatous plaque surgery. Thus, the invasion of coronary artery endothelial cells by Streptococcus mutans OMZ175 underscores a potential role for these bacteria in the pathogenesis of CVD [31]. However, in addition to the bacterial aspects, dental caries is considered as a 'multifactorial' disease, such as many chronic diseases like cancer, CVD, and diabetes, which are the result of the interaction of many genetic, environmental and behavioural risk factors [32].

The correlation between BMI and dental caries scores has been frequently stressed [33-35]. This association might be caused by a carbohydrate rich diet, which rise both dental caries and CVD risks. This dietary pattern could be a factor affected by unhealthy lifestyle, notably poor diet. On the other aspect, body weight alone or included in multivariate statistic models has not been powerful predictor risk for dental caries prevalence and incidence in many studies [36-38]. Fluoride exposure and availability of oral health care services have been suggested as confounders for association between dental caries and childhood overweight [39].

Recent findings on the effect of inadequate glycemic control on increasing the incidence and progression of buccal alterations found in diabetic patients [40] underscores the importance of considering the association of oral health with chronic diseases. Our findings on correlation of DMFS with higher risk for CDVs can be suggested as another confirmatory evidence for the importance of considering multidisciplinary preventive measures against CVD from early life.

\section{Study strengths and limitations}

Cross-sectional studies performed with convenience samples, such as the current one, cannot be generalized to the entire population. However, they can identify risk indicators of those parameters that are significantly associated with the condition being investigated. Whether these risk indicators would be confirmed to act as risk factor remains to be demonstrated in prospective studies. The main strengths of the study are its novelty in the paediatric age group, and its populationbased design.

This study showed higher prevalence of dental caries among adolescents with higher risk of CVD and revealed significant associations between dental caries and CVD risk factors.

\section{Conclusions}

This study showed significant associations between dental caries and CVD risk factors. Given that adolescents with high dental caries were at higher risk of these risk factors, more attention should be paid to oral health, as one of topics for prevention of cardiometabolic disorders. The most significant recommendation concluded 
from this study is to create a sense of responsibility among medical health professionals especially in the community of paediatricians, dentists, and general physicians to inform children and families about the shortand long-term hazards of having high DMFS and poor oral hygiene including their potential association with CVD risk factors. This concept should be taken into account in primordial/primary prevention of CVD.

\section{Conflict of interests}

The authors declare that they have no competing interests.

\section{Acknowledgements}

This study was funded by Research Bureau of Isfahan University of Medical Sciences and Isfahan Cardiovascular Research Centre.

\section{Author details}

'Paediatric Preventive Cardiology Department, Isfahan Cardiovascular Research Centre (WHO Collaborating Centre in Eastern Mediterranean Region), Isfahan University of Medical Sciences, Isfahan, Iran. ${ }^{2}$ Paediatric Dentistry Department, Faculty of Dentistry, Torabinejad Dental Research Centre, Isfahan University of Medical Sciences, Isfahan, Iran. ${ }^{3}$ Faculty of Dentistry, Torabinejad Dental Research Centre, Isfahan University of Medical Sciences, Isfahan, Iran. ${ }^{4}$ Science and Research University, Tehran, Iran.

\section{Authors' contributions}

RK participated in the design of the study, provided the study participants, supervised the study, wrote and edited the manuscript, SM participated in the design of the study, supervised the study and edited the manuscript, TRH conducted the physical examination and participated in editing the manuscript, PP participated in writing and editing the manuscript. All authors read and approved the final manuscript.

Received: 22 March 2010 Accepted: 7 April 2010 Published: 7 April 2010

\section{References}

1. Yusuf S, Reddy S, Ounpuu S, Anand S: Global burden of cardiovascular diseases: part I: general considerations, the epidemiologic transition, risk factors, and impact of urbanization. Circulation 2001, 27:2746-2753.

2. World Health Organization: Global strategy for non-communicable disease prevention and control (Draft) Geneva: WHO 1997, WHO/NCD/GS/97.

3. McGill HC, McMahan CA, Gidding SS: Are Paediatricians responsible for prevention of adult cardiovascular disease? Nat Clin Pract Cardiovasc Med 2009, 6:10-11.

4. Hong YM: Atherosclerotic cardiovascular disease beginning in childhood. Korean Circ J 2010, 40:1-9.

5. Bokhari SA, Khan AA: Growing burden of non-communicable diseases: the contributory role of oral diseases, Eastern Mediterranean Region perspective. East Mediterr Health J 2009, 15:1011-1020.

6. Touger-Decker R: Diet, cardiovascular disease and oral health: promoting health and reducing risk. J Am Dent Assoc 2010, 141:167-170.

7. Santacroce $L$, Carlaio RG, Bottalico L: Does it make sense that diabetes is reciprocally associated with periodontal disease? Endocr Metab Immune Disord Drug Targets 2010

8. Holmlund A, Hedin M, Pussinen PJ, Lerner UH, Lind L: Porphyromonas gingivalis $(\mathrm{Pg})$ a possible link between impaired oral health and acute myocardialinfarction. Int J Cardiol 2009.

9. Haumschild MS, Haumschild RJ: The importance of oral health in longterm care. J Am Med Dir Assoc 2009, 10:667-671.

10. Maloney WJ: Oral health, heart health. J Am Dent Assoc 2009, 140:1218

11. Cullinan MP, Ford PJ, Seymour GJ: Periodontal disease and systemic health: current status. Aust Dent J 2009, 54:562-69.

12. González-Martínez F, Sánchez-Pedraza R, Carmona-Arango L: [Risk indicators for dental caries in preschool children from La Boquilla, Cartagena]. Rev Salud Publica (Bogota) 2009, 11:620-630.
13. Stephenson J, Chadwick BL, Playle RA, Treasure ET: Modelling Childhood Caries Using Parametric Competing Risks Survival Analysis Methods for Clustered Data. Caries Res 2010, 44:69-80

14. Tinanoff $N$, Reisine $S$ : Update on early childhood caries since the Surgeon General's Report. Acad Pediatr 2009, 9:396-403.

15. Peres KG, Peres MA, Araujo CL, Menezes AM, Hallal PC: Social and dental status along the life course and oral health impacts in adolescents: a population-based birth cohort. Health Qual Life Outcomes 2009, 7:95.

16. Sheiham A, Fejerskov O: Caries control for populations. Dental Caries-The Disease and Its Clinical Management London, Blackwell MunksgaardFejerskov O, Nyvad B, Kidd EAM 2003, 304-308.

17. Mobley C, Marshall TA, Milgrom P, Coldwell SE: The contribution of dietary factors to dental caries and disparities in caries. Acad Pediatr 2009, 9:410-414

18. Schroth RJ, Harrison RL, Moffatt ME: Oral health of indigenous children and the influence of early childhood caries on childhood health and well-being. Pediatr Clin North Am 2009, 56:1481-1499.

19. Ylöstalo PV, Järvelin MR, Laitinen J, Knuuttila ML: Gingivitis, dental caries and tooth loss: risk factors for cardiovascular diseases or indicators of elevated health risks. J Clin Periodontol 2006, 33:92-101.

20. Lohman TG, Roche AF, Martorell R: Anthropometric Standardization Reference Manual Campaign, IL, Human Kinetics Publishers Inc 1988.

21. Kuczmarski RJ, Ogden CL, Grummer-Strawn LM: CDC growth charts: United States. Adv Data 2000, 314:1-27.

22. National High Blood Pressure Education Program Working Group on High Blood Pressure in Children and Adolescents: The Fourth Report on the Diagnosis, Evaluation, and Treatment of High Blood Pressure in Children and Adolescents. Pediatrics 2004, 114:555-576.

23. Warnick GR, Benderson J, Albers JJ: Dextran sulfate-magnesium precipitation procedure for quantitation of high-density lipoprotein cholesterol. Clin Chem 1982, 28:1379-1382.

24. Kavey RE, Daniels SR, Lauer RM, Atkins DL, Hayman LL, Taubert K, American Heart Association: American Heart Association guidelines for primary prevention of atherosclerotic cardiovascular disease beginning in childhood. Circulation 2003, 107:1562-1566.

25. Genuth S, Alberti KG, Bennett P, Buse J, Defronzo R, Kahn R, Kitzmiller J, Knowler WC, Lebovitz H, Lernmark A, Nathan D, Palmer J, Rizza R, Saudek C, Shaw J, Steffes M, Stern M, Tuomilehto J, Zimmet P: Expert Committee on the Diagnosis and Classification of Diabetes Mellitus: Follow-up report on the diagnosis of diabetes mellitus. Diabetes Care 2003, 26:3160-3167.

26. World Health Organization: Dentition status and treatment needs. Oral health surveys: basic methods, Geneva, 4 1997, 40-47.

27. Johansson I, Tidehag P, Lundberg V, Hallmans G: Dental Status, diet and cardiovascular risk factors in middle-aged people in northern Sweden. Community Dent Oral Epidemiol 1994, 22:431-436.

28. Larsson B, Johnson I, Hallmans G, Ericsson T: Relationship between dental caries and risk factors for atherosclerosis in Swedish adolescents. Community Dent Oral Epidemiol 1995, 23:205-210.

29. Larsson B, Johansson I, Weinehall L, Hallmans G, Ericson T: Cardiovascular disease risk factors and dental caries in adolescents: effect of a preventive program in Northern Sweden (the Norsjö project). Acta Paediatr 1997, 86:63-71.

30. Grau AJ, Becher H, Ziegler CM, Lichy C, Buggle F, Kaiser C, Lutz R, Bültmann S, Preusch M, Dörfer CE: Periodontal disease as a risk factor for ischemic stroke. Stroke 2004, 35:496-501.

31. Abranches J, Zeng L, Bélanger M, Rodrigues PH, Simpson-Haidaris PJ, Akin D, Dunn WA Jr, Progulske-Fox A, Burne RA: Invasion of human coronary artery endothelial cells by Streptococcus mutans OMZ175. Oral Microbiol Immunol 2009, 24:141-145.

32. Fejerskov O: Changing paradigms in concepts on dental caries: consequences for oral health care. Caries Res 2004, 38:182-191.

33. Alm A, Fåhraeus C, Wendt LK, Koch G, Andersson-Gäre B, Birkhed D: Body adiposity status in teenagers and snacking habits in early childhood in relation to approximal caries at 15 years of age. Int J Paediatr Dent 2008 18:189-196.

34. Marshall TA, Eichenberger-Gilmore JM, Broffitt BA, Warren JJ, Levy SM: Dental caries and childhood obesity: roles of diet and socioeconomic status. Community Dent Oral Epidemiol 2007, 35:449-458.

35. Willershausen B, Moschos D, Azrak B, Blettner M: Correlation between oral health and body mass index in 2071 primary school pupils. Eur J Med Res 2007, 12:295-299. 
36. Hong L, Ahmed A, McCunniff M, Overman P, Mathew M: Obesity and Dental Caries in Children Aged 2-6 Years in the United States: National Health and Nutrition Examination Survey 1999-2002. J Public Health Dent 2008, 68:227-233.

37. Pinto $\mathrm{A}$, Kim $\mathrm{S}$, Wadenya $\mathrm{R}$, Rosenberg $\mathrm{H}$ : Is there an association between weight and dental caries among pediatric patients in an urban dental school? A correlation study. J Dent Educ 2007, 71:1435-1440.

38. Moreira PV, Rosenblatt A, Severo AM: Prevalence of dental caries in obese and normal-weight Brazilian adolescents attending state and private schools. Community Dent Health 2006, 23:251-253.

39. Gerdin EW, Angbratt M, Aronsson K, Eriksson E, Johansson I: Dental caries and body mass index by socio-economic status in Swedish children. Community Dent Oral Epidemiol 2008, 36:459-465.

40. Negrato CA, Tarzia O: Buccal Alterations in Diabetes Mellitus. Diabetol Metab Syndr 2010.

doi:10.1186/1758-5996-2-22

Cite this article as: Kelishadi et al:: Association of cardiometabolic risk factors and dental caries in a population-based sample of youths.

Diabetology \& Metabolic Syndrome 2010 2:22.

\section{Submit your next manuscript to BioMed Central} and take full advantage of:

- Convenient online submission

- Thorough peer review

- No space constraints or color figure charges

- Immediate publication on acceptance

- Inclusion in PubMed, CAS, Scopus and Google Scholar

- Research which is freely available for redistribution

Submit your manuscript at www.biomedcentral.com/submit 